University of Nebraska - Lincoln DigitalCommons@University of Nebraska - Lincoln

DBER Speaker Series

Discipline-Based Education Research Group

3-19-2015

\title{
The Effectiveness of E-Coaching in Rural Science Classrooms
}

\author{
Gwen Nugent \\ University of Nebraska - Lincoln, gnugent@unl.edu
}

Follow this and additional works at: http:// digitalcommons.unl.edu/dberspeakers

Part of the Educational Assessment, Evaluation, and Research Commons

Nugent, Gwen, "The Effectiveness of E-Coaching in Rural Science Classrooms" (2015). DBER Speaker Series. 74.

http://digitalcommons.unl.edu/dberspeakers/74

This Presentation is brought to you for free and open access by the Discipline-Based Education Research Group at DigitalCommons@University of Nebraska - Lincoln. It has been accepted for inclusion in DBER Speaker Series by an authorized administrator of DigitalCommons@University of Nebraska - Lincoln. 


\title{
Abstract for DBER Group Discussion on 2015-03-19
}

Presenter(s), Department(s):

Gwen Nugent

Research Professor

Nebraska Center for Research on Children, Youth, Families and Schools

University of Nebraska-Lincoln

Title:

The Effectiveness of E-Coaching in Rural Science Classrooms

\begin{abstract}
:
This presentation will present final results of a research project funded by the U.S. Department of Education and conducted by the National Center for Research on Rural Education at UNL. The study is a randomized control trial with 119 rural middle and high school science teachers in Nebraska and lowa. It examines the impact of professional development on guided scientific inquiry with technologydelivered follow-up coaching (treatment) versus no professional development (control) on teacher and student inquiry knowledge, skills, self-efficacy and attitudes. This presentation will provide an overview of the project, focusing on the coaching processes and procedures, and present final results.
\end{abstract}




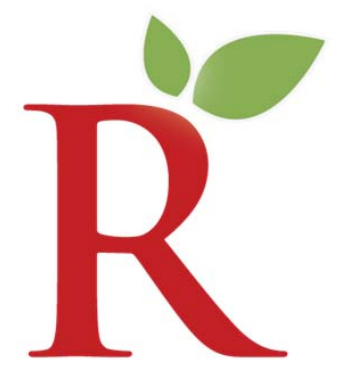

National Center for Research on

Rural Education $\left(\mathrm{R}^{2} \mathrm{Ed}\right)$

The Effectiveness of E-Coaching in

Rural Science Classrooms

Gwen Nugent, James Houston, Gina Kunz, Irina Kalutskaya, Greg Welch, ChaoRong Wu

Nebraska

Lincoln 


\section{K-12 Teacher Professional Development}

- Research has shown that teacher PD should include follow-up support that is directly tied to what is happening in a teacher's classroom

- Technology can connect teachers in rural areas with instructional coaches 


\section{CSI: Coaching Science Inquiry in Rural Schools}

- CSI is a research study conducted by the National Center for Research on Rural Education $\left(R^{2} E d\right)$ at the University of Nebraska-Lincoln

- Funded by the U.S. Department of Education

- Key PD element is technology-delivered coaching

- Randomized controlled trial

- Involves 124 middle/high school rural teachers 


\section{CSI: COACHING SCIENCE INQUIRY IN RURAL SCHOOLS}

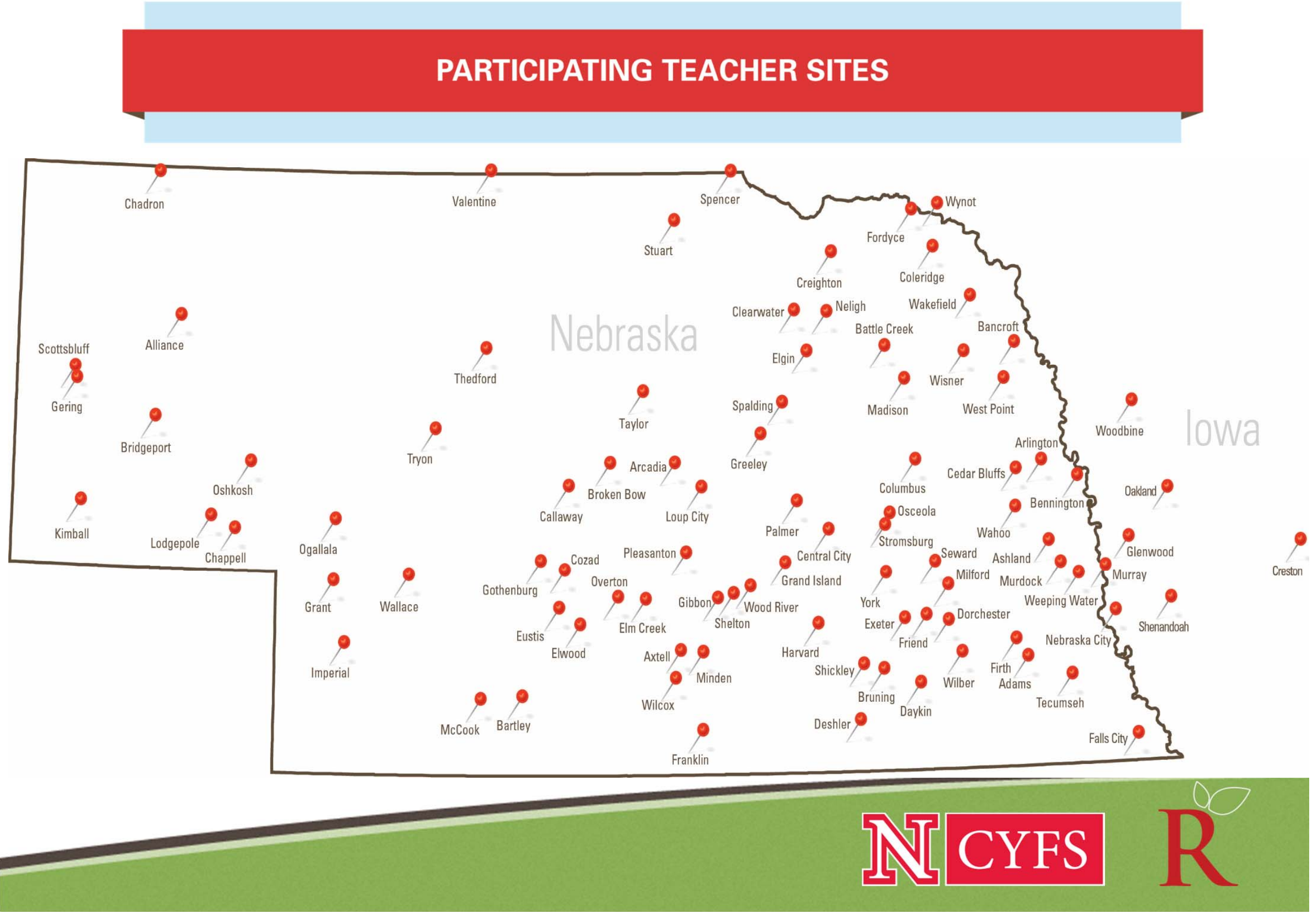




\section{CSI Research Study Research Question}

What is the impact of professional development on guided scientific inquiry with follow-up coaching (treatment) versus no professional development (control) on (a) teacher inquiry knowledge, skills, selfefficacy, and beliefs and (b) student inquiry knowledge, skills, engagement and science attitudes? 


\title{
CSI Inquiry Approach
}

- Guided inquiry instruction with scaffolding

\author{
NOT
}

Verification of teacher-presented content through demonstration 


\section{Summer Institute}

- 8-day workshop in Lincoln using evidence-based strategies

- Modeling by faculty, expert teachers, and coaches with commentary

- Teacher practice of new skills

- Feedback from coaches, peers, and faculty

- Use of video examples of pedagogical strategies (concept identification, questioning, scaffolding)

- Teachers provided with 6-8 week inquiry units

- Provided a foundation for a common language and shared understanding of what inquiry is and how to implement it

Over 60,000 miles traveled by teachers for Summer Institute 


\section{Coaching}

- Coaches were experienced science teachers

- Nearly 100 years of classroom experience at both middle and high school level

- Coach training was one week with video examples and modeling

- Establishing effective teacher-coach relationships

- Co-creating behavioral targets for teacher instruction

- Skills for teacher observation

- Providing feedback

- Technology training 


\section{E-Coaching Process}

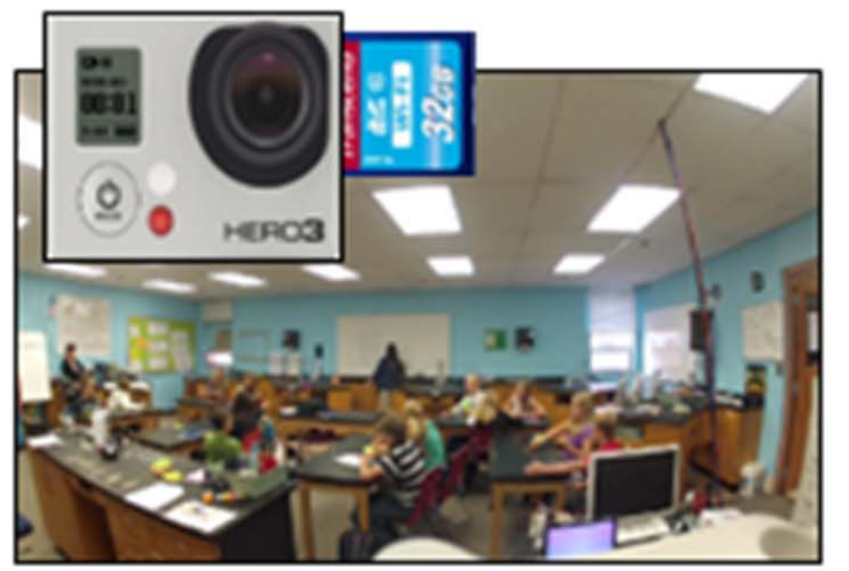

Teacher

囚 Classroom Implementation
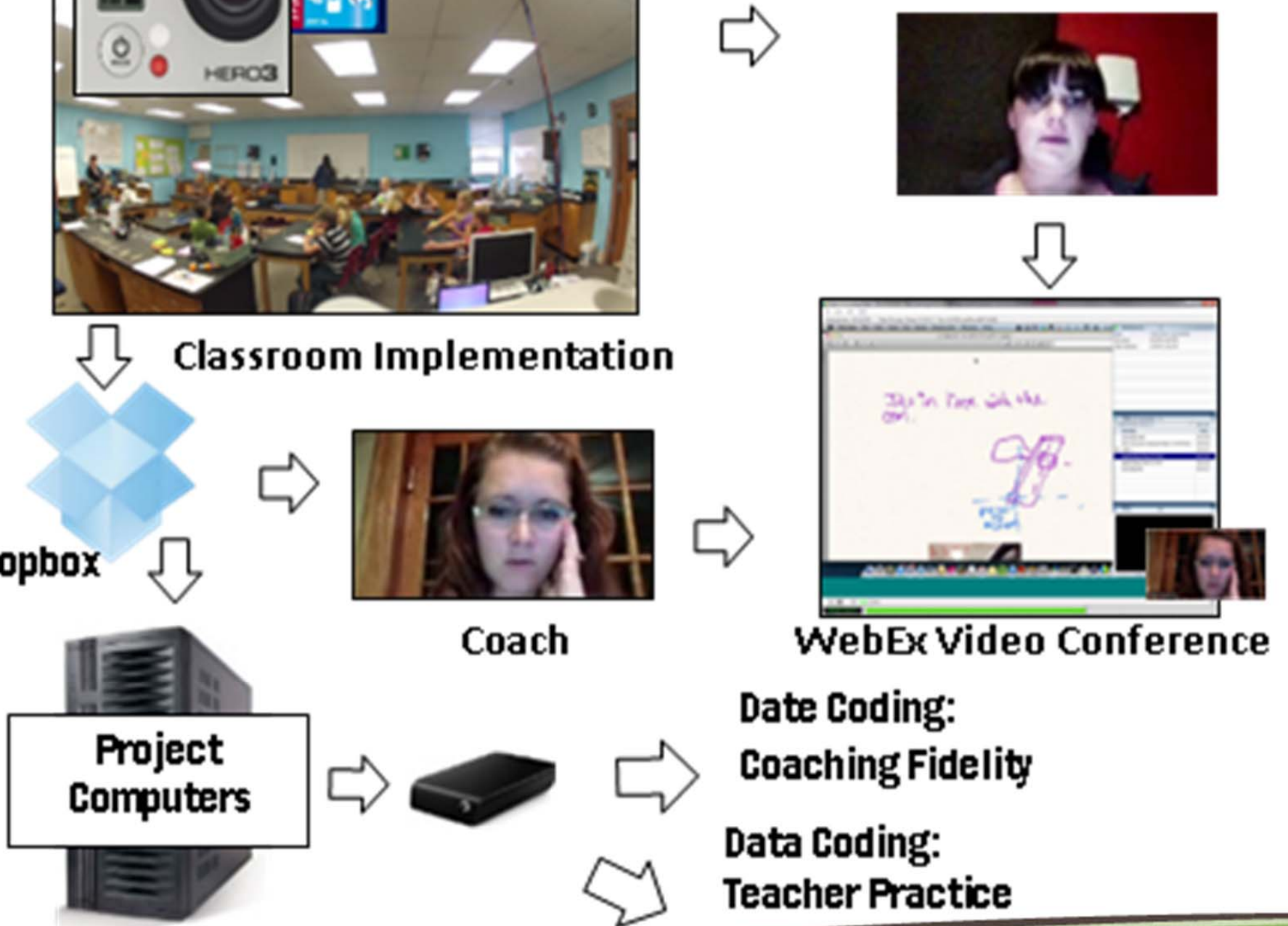

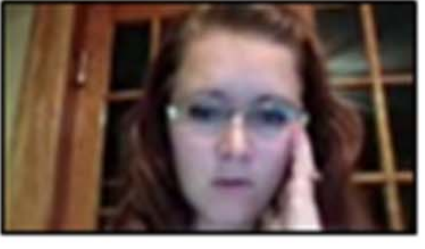

Coach
Date Coding:

Coaching Fidelity

Data Coding:

ST Teacher Practice 


\section{Use of Technology for Multiple Purposes}

- Teacher recording classroom lessons for review by themselves, coaches, and data coders

- Delivery of video files from teachers to coaches and data coders

- Connecting teachers and coaches for the synchronous coaching sessions

- Data collection and coding 


\section{Teacher Recording of Classroom Instruction}

- Teachers video recorded lessons using GoPro cameras and mics

- Teachers offloaded videos by either removing the storage card or connecting GoPro to computer 


\section{Transfer of Video Files to Coaches}

- Files were uploaded to DropBox

- Project-developed software automatically uploaded new files to the main project computer 


\section{E-Coaching}

- Usually twice a week for about 45 min. each over a 6-8 week period

- Bi-directional feedback based on videorecorded classroom lesson

- Used WebEx

- Two-way video/audio

- Playback of video examples of classroom instruction

- Sharing of documents and desktop

- Recording capability 


\section{Technology Use in Data Collection and Coding}

- 6,000-8,000 hours (7 TB) of classroom video to code using three observational instruments

- Also recorded coaching sessions to assess coach adherence to established coaching protocols 


\section{Research Study Results}




\section{Teacher Demographics}

- 124 Teachers from 109 schools

- 70\% Female / 30\% Male

- Average of 14 years of teaching experience

- $50 \%$ have master's degree 


\section{CSI Students}

- Approximately 1800 Students from Nebraska and lowa schools

- 900 High School Students (9-12)

- 900 Middle School Students (6-8) 


\section{Study Outcomes}

- Based on student scientific inquiry abilities/practices specified in standards

- Questioning

- Designing and conducting a scientific investigation

- Data collection, analysis and interpretation

- Developing explanations

- Communicating results

- Focus on teacher behaviors needed to elicit student skills 


\section{Teacher Results}

63 treatment teachers

61 control teachers 


\section{Teacher Inquiry Beliefs}

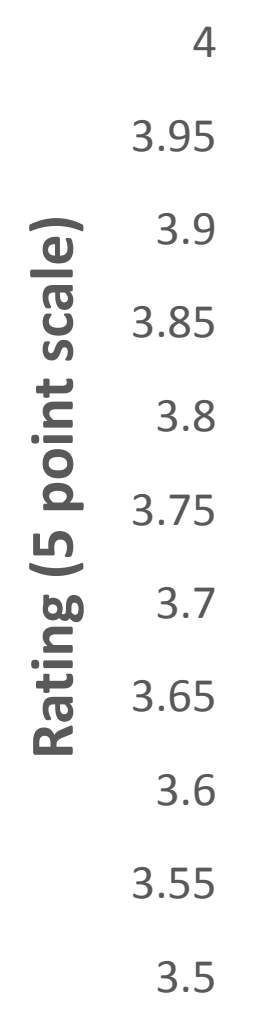

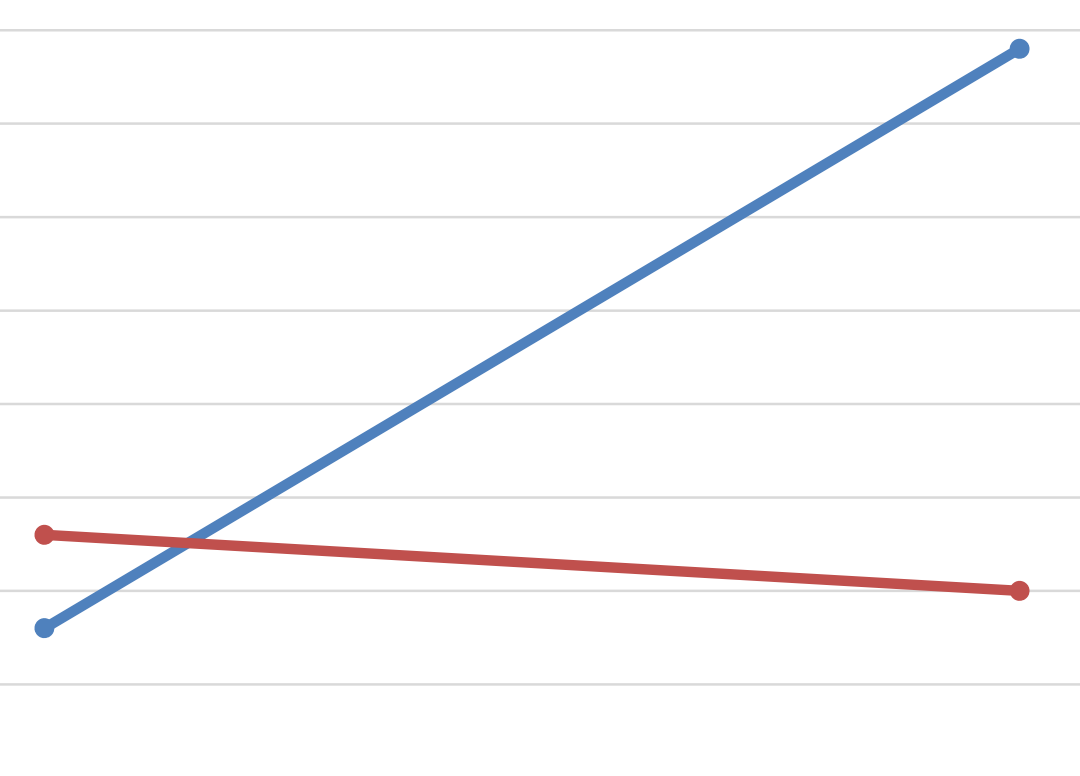

Baseline

EndYear

$\rightarrow$ Treatment $\rightarrow$ Control 


\section{Teacher Inquiry Knowledge}

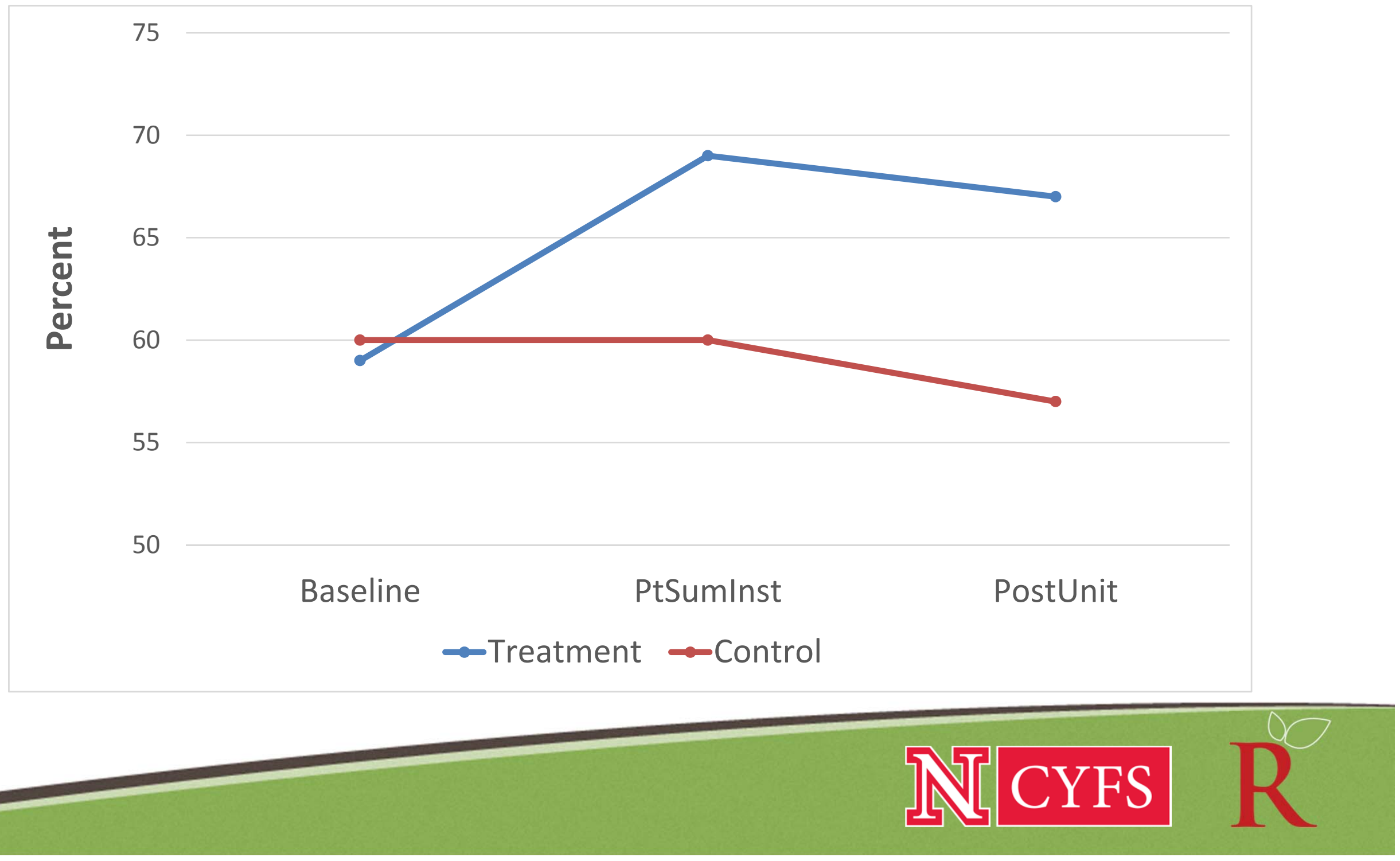




\section{Teacher Self-Efficacy}

100

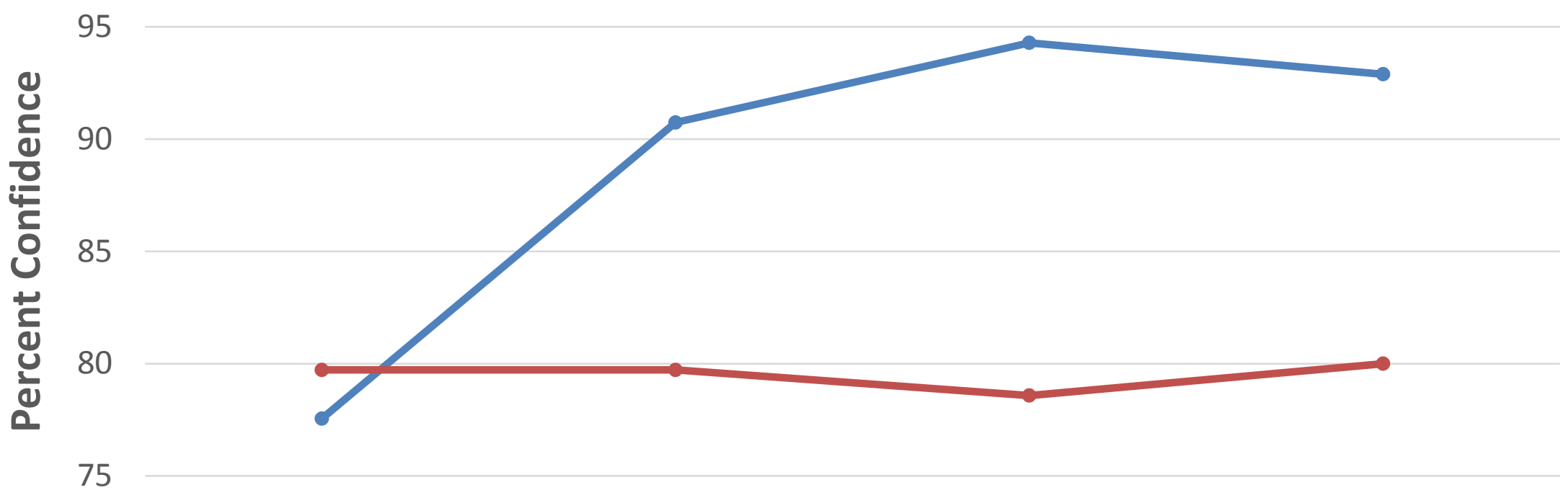

70

Baseline

PtSumlnst

PtUnit

EndYear

$\rightarrow$ Treatment $\rightarrow$ Control 


\section{Teacher Instructional Practice}

- Three observational instruments

- Teacher Inquiry Rubric (project-developed)

- EQUIP (Electronic Quality of Inquiry Protocol, Marshall, 2009)

- Partial Interval Classroom Inquiry Observation System ( $\mathrm{PICl}$; project-developed) 


\section{Teacher Inquiry Rubric}

- Six constructs based on student scientific inquiry abilities specified in standards (questioning, investigation, collect data, explanation, communication \& application)

- Focuses on teacher behaviors needed to elicit student skills 


\section{TIR Proficiency Levels}

1. Pre - No evidence of instruction for particular skill

2. Developing - Direct presentation by teacher using lecture or demonstration

3. Proficient - Teacher use of guiding questions, experiences, scaffolding and/or feedback

This is guided inquiry!

4. Exemplary - Use of guiding questions, scaffolds, and/or feedback to guide students to perform the skill 


\section{Teacher Inquiry Rubric Results}

3.5

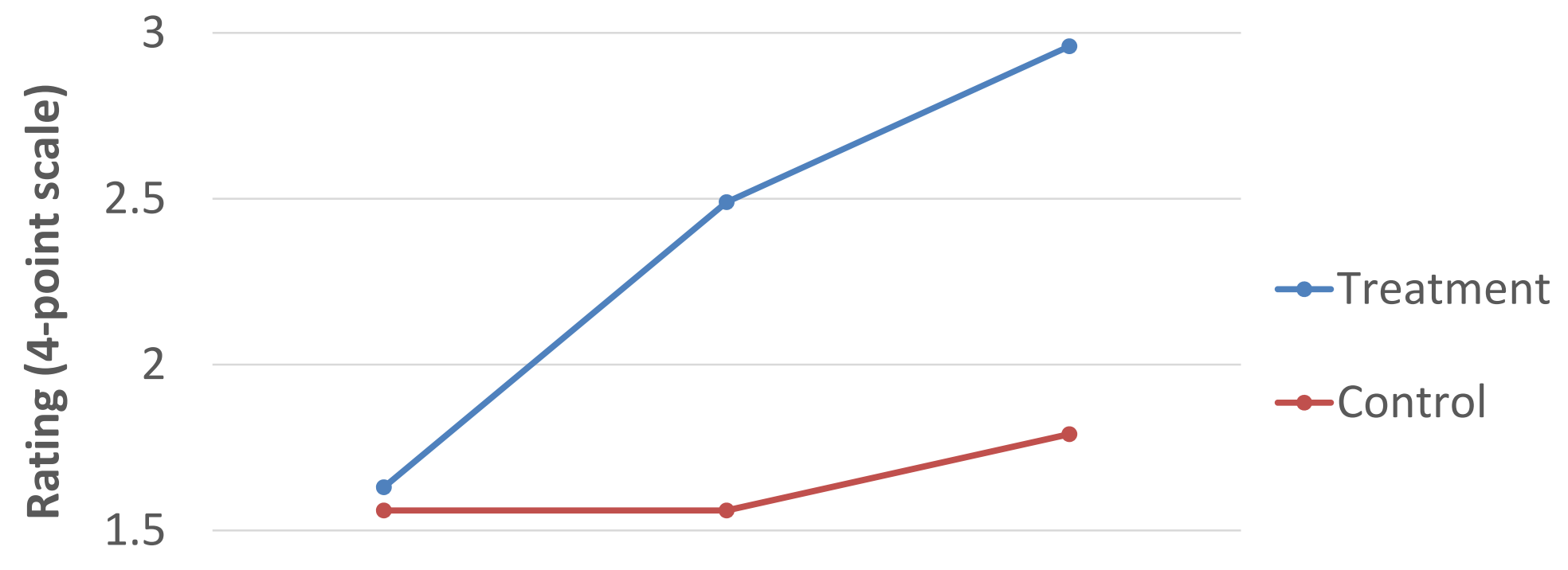

1

Baseline

PtSumlnst

PtUnit

$\mathbb{N}$ CYFS 


\section{EQUIP}

\section{Electronic Quality of Inquiry Protocol}

- 19 indicators with overall construct scores targeting areas of reform or inquiry-based instruction that are linked to student achievement.

Instruction (How do I lead?)

Discourse (How do we interact?)

Assessment (How does instruction influence achievement?)

Curriculum (What guides teaching and learning?) 


\section{EQUIP Results}

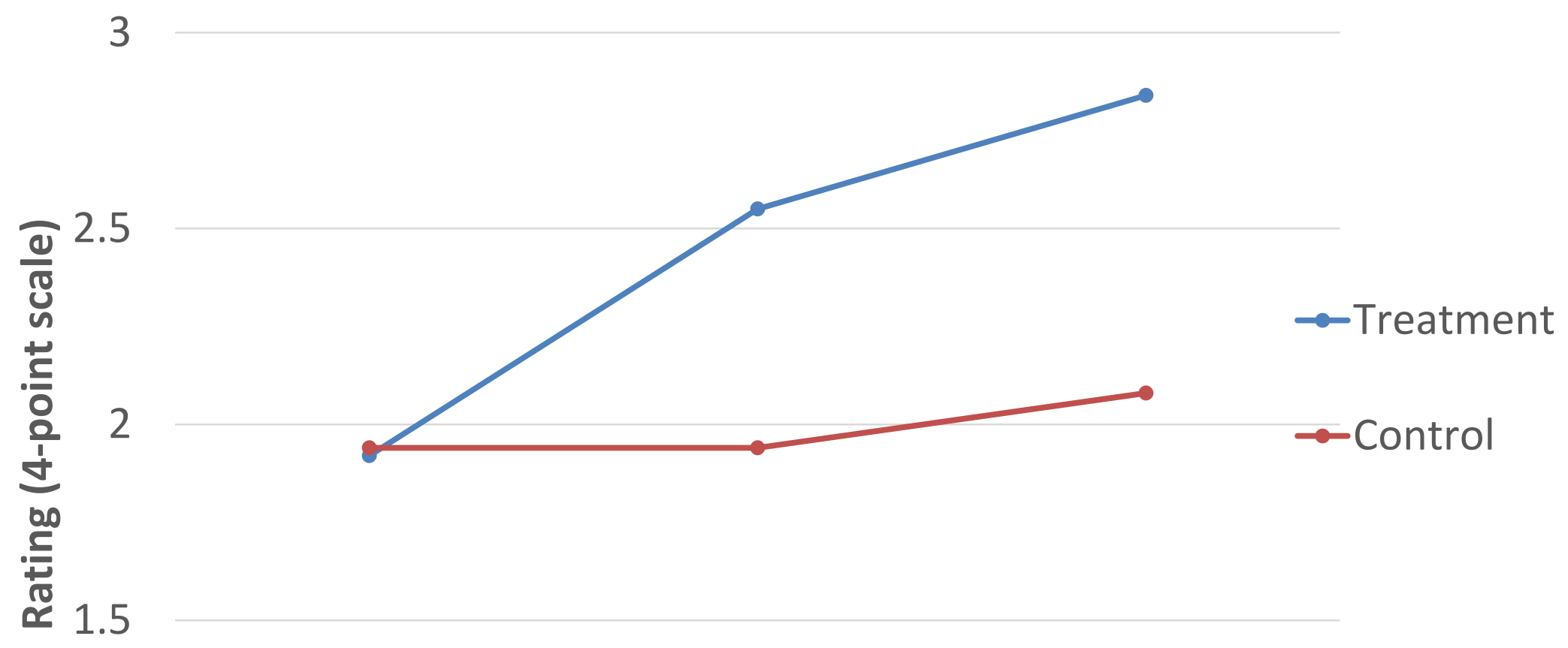

1

Baseline

PtSumlnst

PtUnit 


\section{Partial Interval Classroom Inquiry (PICl) Observation System for Teachers (PICl-T)}

- Interval recording procedure: $15 \mathrm{sec}$ intervals

- Records whether teacher is presenting or not presenting inquiry instruction during each interval 


\section{PICl-T Results}

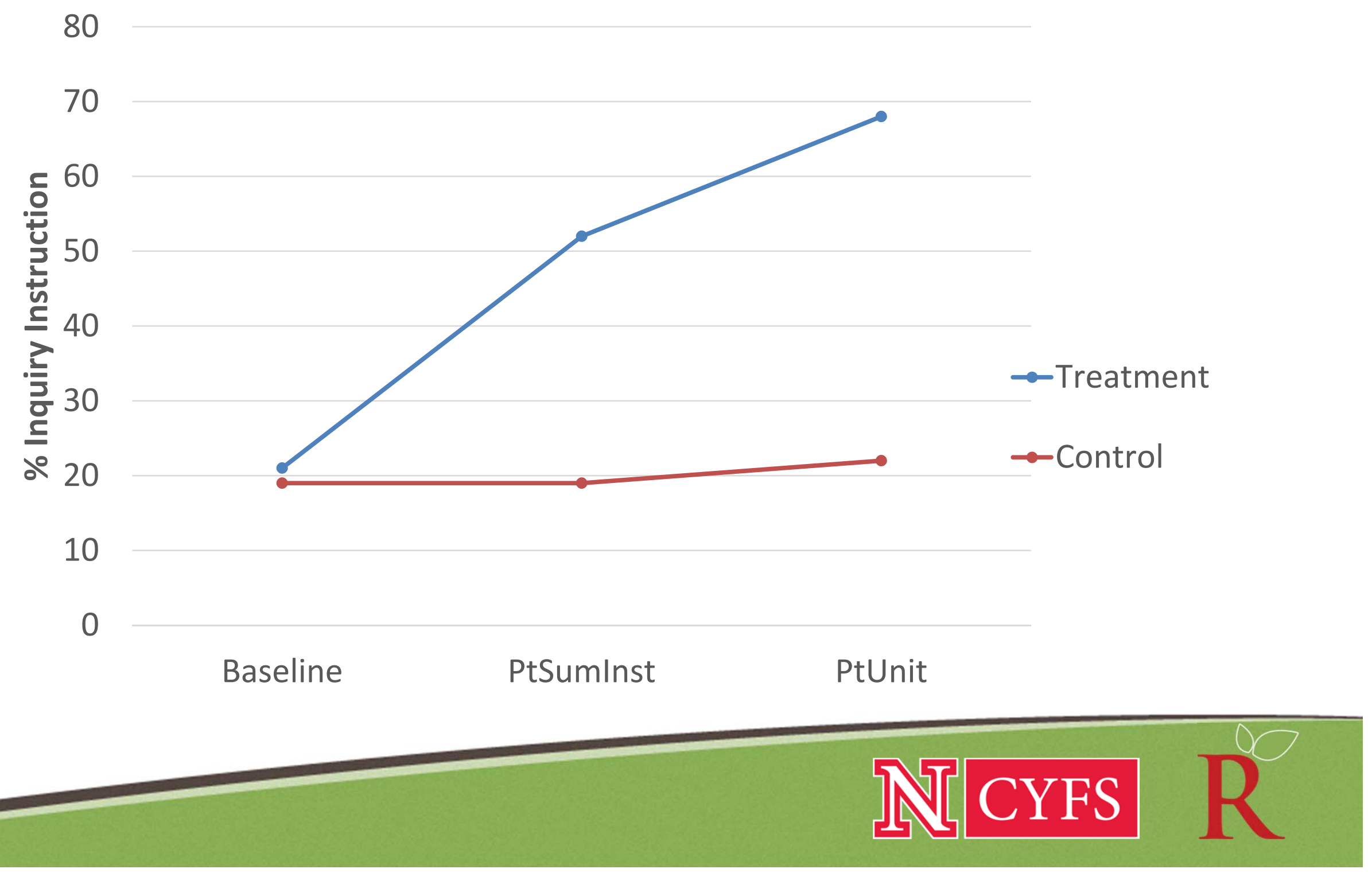




\title{
Student Results
}

\author{
900 Treatment \\ 900 Control
}




\section{Student Findings: MS Inquiry Knowledge}

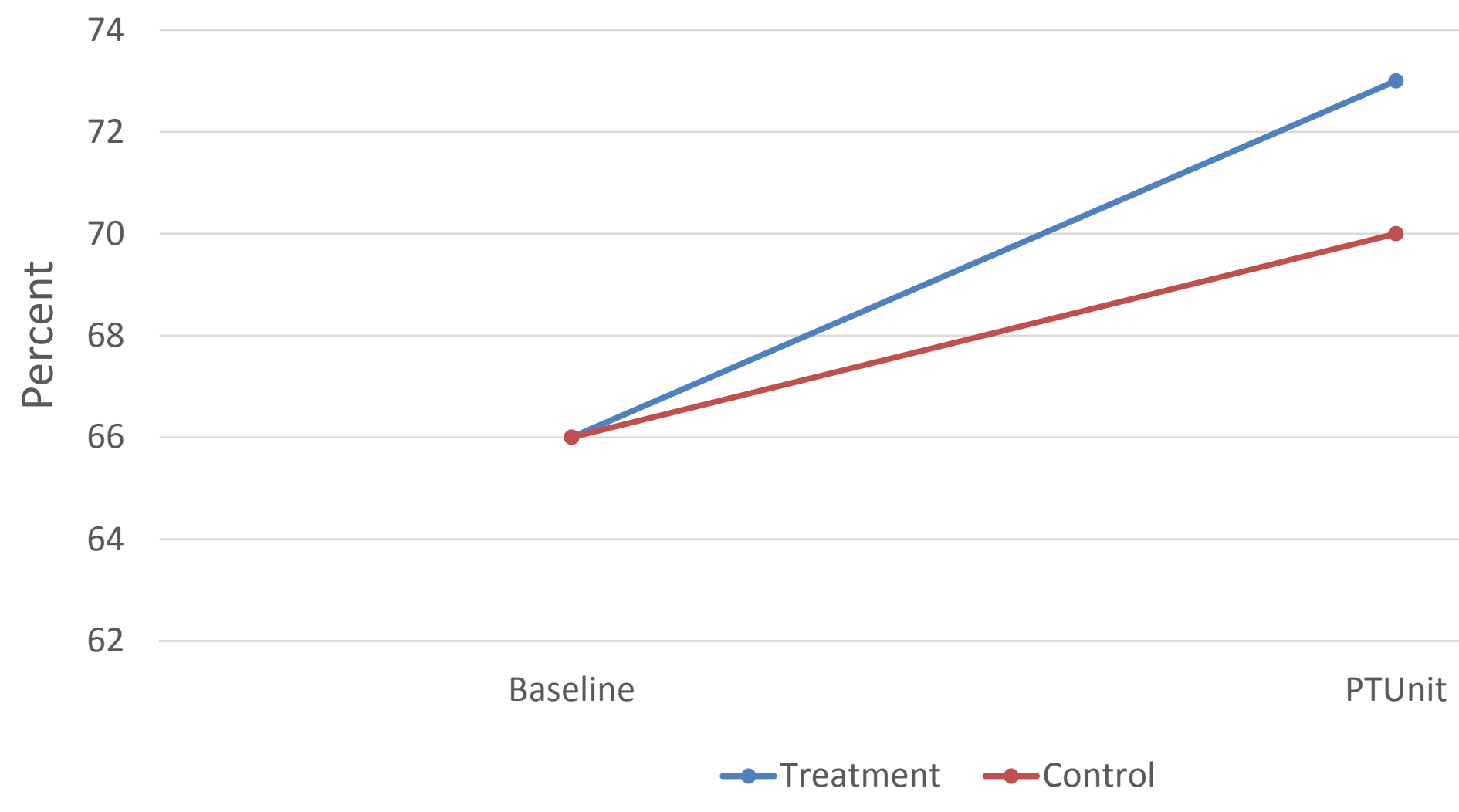




\section{Student Inquiry Skills}

- Instrument: Student Inquiry Rubric (SIR)

- Four-level rubric investigating student's inquiry practices (questioning, collecting data, investigating, developing explanation from evidence, communicating results)

- Adapted from instrument developed by NE ESU 3

- Completed by teacher for each student in the study 


\section{Student Inquiry Rubric Results}

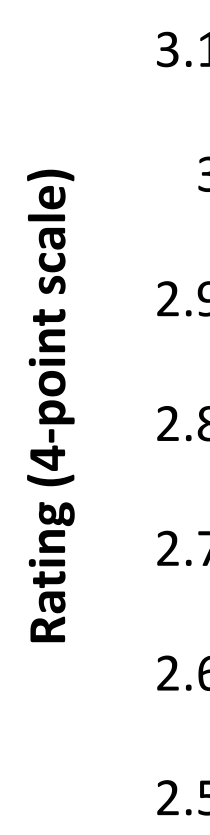

3.1

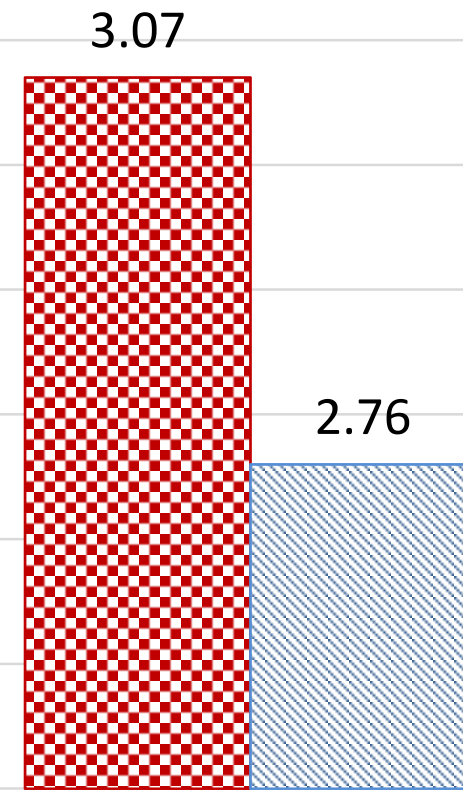

Middle School

High School

B Treatment

$\mathbb{N}$ Control 


\section{Student Inquiry Rubric Results}

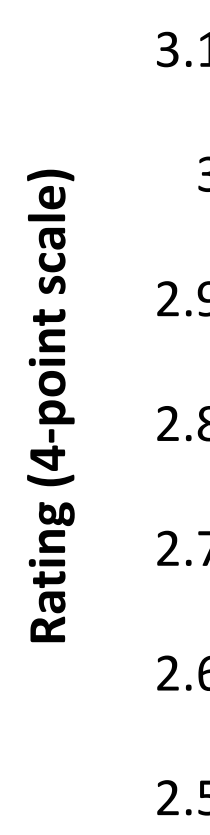

3.1

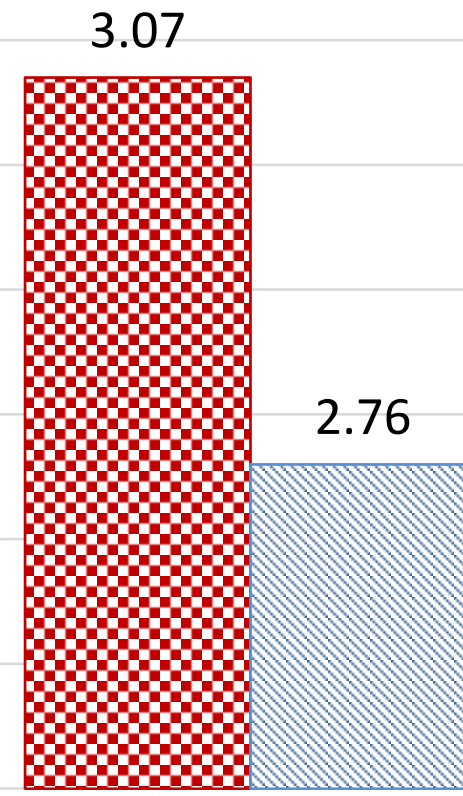

Middle School

High School

B Treatment

$\mathbb{N}$ Control 


\section{NeSA \\ Science}

- No significant differences in treatment and control for either middle or high school, although middle school results are in the hypothesized direction. 


\section{$\mathrm{PICl}$-Student}

- Used 15 second interval recording procedure

- Student Response type: On-Task, Off-Task, Inquiry Engaged

- Observe one student for 1 minute, then switch to another student until all students included and then start over

- Class measure based on individual student responses 


\section{$\mathrm{PICl}-\mathrm{S}$}

Student Inquiry Engagement

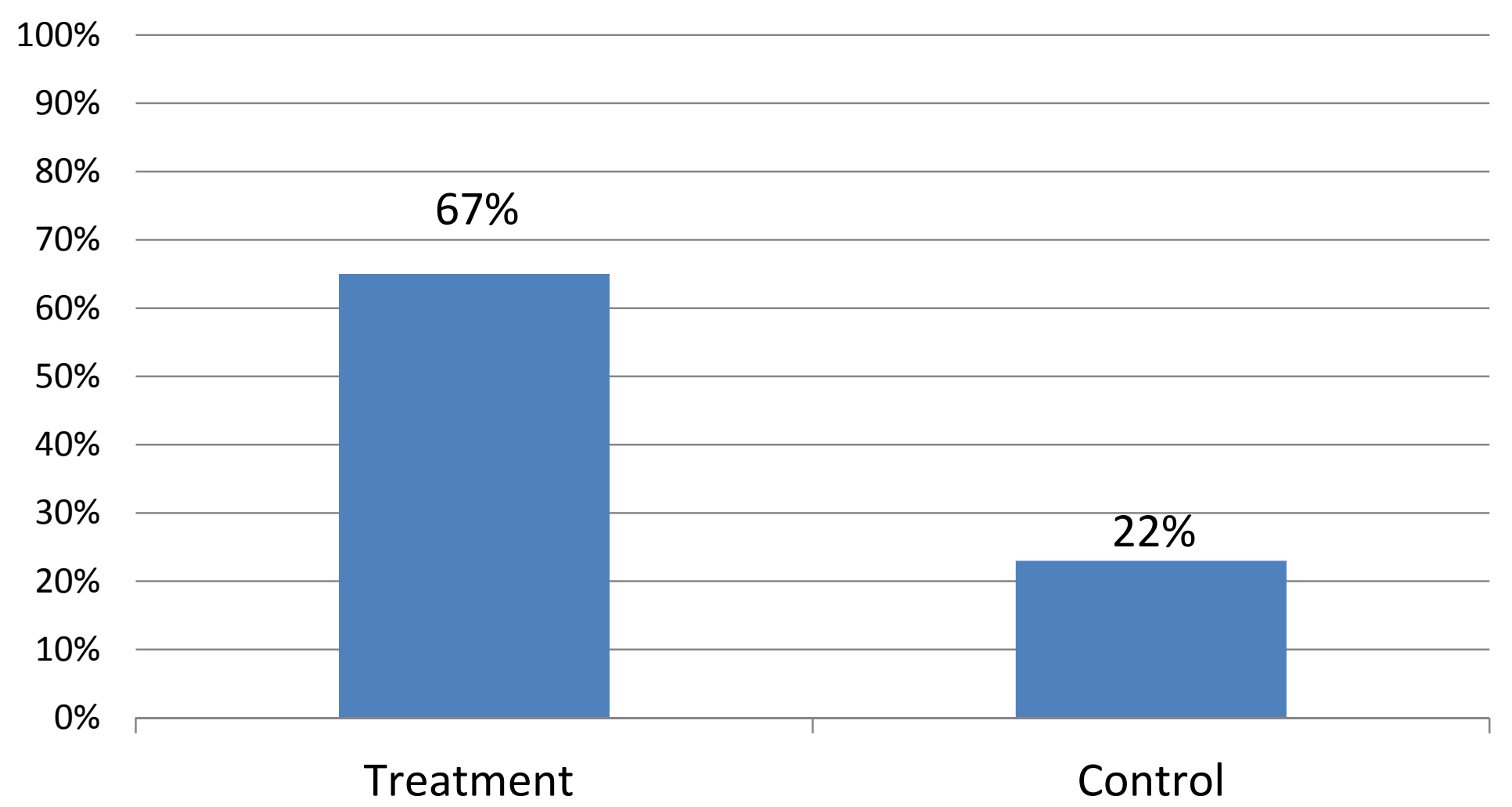




\section{Coaching Evaluation}

Coaching encouraged self-reflection

Coaching changed my instructional practices to benefit student learning.

Coaching improved my teaching skills

Coach helped me identify teaching strategies to support student outcomes.

CSI required too much time for the benefit I gained

Overall coaching rating 


\section{Technology Advantages: Coaching}

- Eliminated need for coaches to travel to school site

\section{Huge \$ savings}

- Anywhere, anytime advantages for both coaches and teachers

- Coaching sessions were scheduled weekends, early mornings, and late evenings

- Physical separation of coaches meant they were viewed as separate from the school administration

- Allowed teachers to review their lessons

- Allowed sharing of video clips during coaching

- Videos provided a teaching portfolio 


\section{Technology Advantages: Data Collection and Coding}

- Coders could stop and review recording

- Eliminated need for coders to travel to school site

- Coders could work anywhere with computer access

- Permitted flexibility in reliability coding

- Allowed for coding of fidelity in coaching sessions 


\section{Technology Challenges: Coaching}

- Teachers were unfamiliar with web-based videoconferencing

- Teachers needed hands-on practice with technology

- Large video files required long transfer times and large storage capability

- Project required ongoing troubleshooting at regional and local levels 


\section{Technology Challenges: Data Collection and Coding}

- Audio/Video recording quality varied greatly

- Coding video was a difficult, time consuming process

- Coders typically watched video $2-3$ times to code three instruments

- Getting coders trained to established criteria was challenging

- IRB issues with video recording 


\section{Lessons Learned}

- Value of technology and video-based data collection

- Coding videos of classroom instruction and student behaviors is challenging and time consuming

- Power of watching videos for teacher self-reflection and to lead to change in instructional practice

- Power of the repeated practice for teachers to effect change

- Quality of science teachers in rural context - high performing teachers in low resource areas

- Coaching relationship established and maintained across distance and with a non-evaluative role

- Coaching has a powerful impact on teacher classroom instruction 


\section{View from the CSI Teachers}

CSI Website

http://r2ed.unl.edu/CSI/ 


\section{Contact Information}

Gwen Nugent

gnugent@unl.edu

$$
\text { 472-1009 }
$$

National Center for Research on Rural Education

216 Mabel Lee Hall

Lincoln, NE 68583-0235

CSIRuralSchools.unl.edu 


\section{Theory of Change}

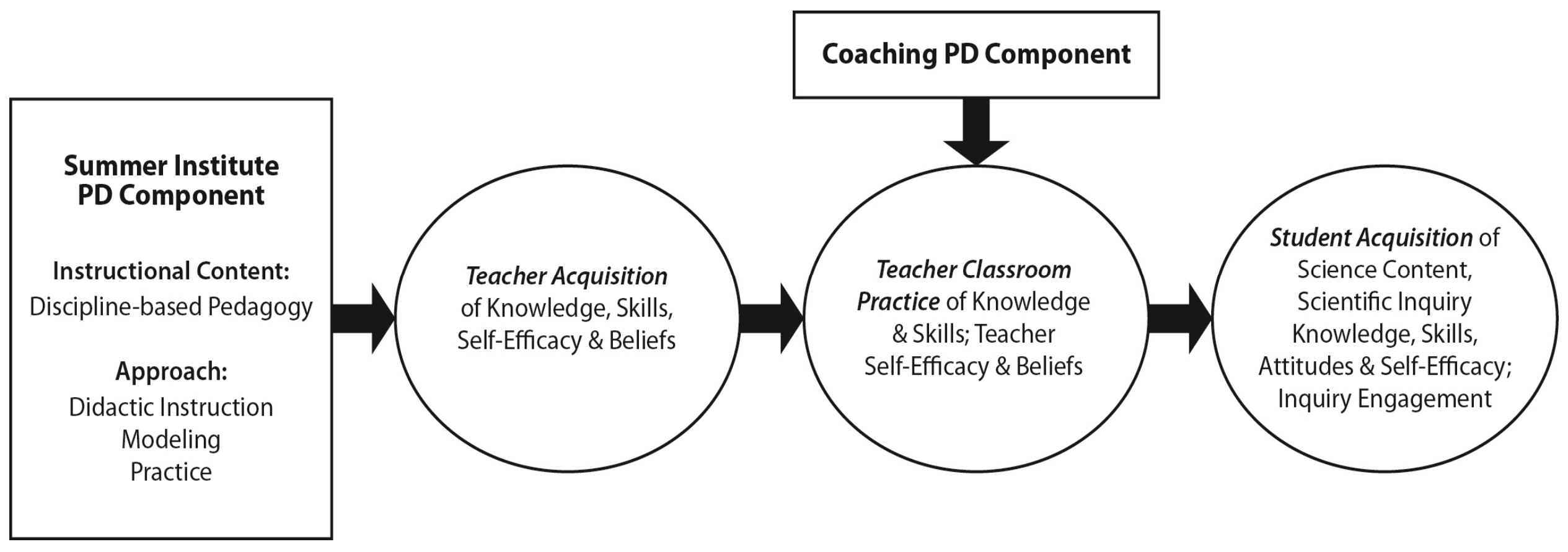

